\title{
ENSINO DE LÍNGUA PORTUGUESA NA EDUCAÇÃO BÁSICA: A IMPORTÂNCIA DO PLANEJAMENTO NO ESTÁGIO SUPERVISIONADO
}

\author{
Larissa Marcelly Farias Almeida* \\ Maria Augusta Gonçalves de Macedo Reinaldo**
}

RESUMO: Neste artigo discutimos sobre a importância do ensino de língua materna (FRANCHI, 1987, GERALDI, 1997, BEZERRA; REINALDO, 2019) com foco no planejamento de ensino (VASCONCELOS, 2002, LUCKESI, 2011, LIBÂNEO, 2013; MENEGOLLA E SANT'ANNA, 2014). Nesse contexto, a questão norteadora da pesquisa é: O que os alunos em estágio supervisionado entendem por planejamento? Para respondermos a esse questionamento, o objetivo geral desse artigo é analisar como os estagiários em Letras - Língua Portuguesa de uma instituição pública, planejam o ensino de língua. Para coleta e geração de dados foram realizadas entrevistas semiestruturadas com três estudantes do curso de Letras - Língua Portuguesa matriculados no componente curricular Estágio Supervisionado; em seguida, foi realizada a coleta dos planos de ensino por eles elaborados; por fim, foi feita a coleta dos relatórios individuais de estágio supervisionado. Os resultados mostram que mesmo fazendo parte da mesma instituição, cursando os mesmos períodos e componentes curriculares, os colaboradores apresentam uma visão diferente sobre a relevância do planejamento enquanto documento de escrita praxiológica. Também é possível perceber que em determinados momentos o dizer afirmado na entrevista não é coerente com o registrado nos documentos (relatórios e planos). Além disso, os dados revelam a tendência dos alunos a dissociarem a escrita da análise linguística, e aproximarem mais os eixos: leitura e análise linguística.

PALAVRAS-CHAVE: Didatização; Ensino de Língua; Planejamento.

\section{Introdução}

$\mathrm{O}$ ato de planejar não é recente, nem surgiu na/para a esfera escolar. Desde os tempos mais remotos em que se têm registros dessa prática, o ser humano já planejava o ato de caçar, pescar, atacar, plantar e colher, por exemplo, o que a remete ao ato de pensar e prever necessidades, obstáculos e estratégias para atender a um dado objetivo.

Nesse sentido, planejar "é (uma) atividade intencional pela qual se projetam fins e se estabelecem meios para atingi-los. Por isso, não é neutro, mas ideologicamente comprometido" (LUCKESI, 2011, p. 124).

\footnotetext{
${ }^{*}$ Mestranda em Letras pela Universidade Federal de Campina Grande (UFCG).

** Doutora em Linguística pela Universidade Federal de Pernambuco (UFPE). Professora titular da Universidade Federal de Campina Grande (UFCG).
} 
Nos cursos de formação de professores, o componente curricular Estágio Supervisionado é estruturado em algumas etapas: a observação da turma, o planejamento e a execução das aulas. Trata-se de um componente curricular que envolve a participação de duas instituições distintas de ensino, relacionando os diferentes indivíduos, em diferentes posições sociais, tecendo uma rede complexa e dinâmica de (retro)ações (SILVA, 2014).

Por isso, é necessário que os curso de licenciaturas formem um professor, não só capaz de mediar um conteúdo, mas também de teorizar, planejar, avaliar e refletir criticamente sobre as teorias, métodos e sua própria prática. O estágio não deve ter o caráter de repetição de atitudes ou instrumentos, mas um momento de reflexão em que o objetivo ultrapasse "dar aula em uma escola", visualizando a contribuição real e reflexiva para prática docente. Para isso o licenciando deverá planejar as ações, didatizar e articular conteúdos e mediar os assuntos previstos em sala de aula, além de associar todas essas atitudes à reflexão sobre sua prática.

Reconhecendo a importância do ato de planejar, e sabendo que é na graduação, em específico no estágio supervisionado que esse processo é exigido, nos perguntamos: O que os alunos em estágio supervisionado entendem por planejamento? Para respondermos a esse questionamento, o objetivo geral desse artigo é analisar como os estagiários em Letras - Língua Portuguesa de uma instituição pública, planejam o ensino de língua.

Este artigo está organizado em cinco seções, além desta introdução e das referências. Na primeira seção discutimos diacronicamente sobre o ensino de língua e sua relevância. A segunda seção contempla discussões acerca de planejamento e didatização de conteúdos. $\mathrm{Na}$ terceira seção situa-se as questões metodológicas da pesquisa. Na quarta seção apresentamos a análise dos dados. Por fim, na quinta e última seção, apresentamos as considerações finais.

\section{Ensino de língua portuguesa}

Desde a colonização, principalmente por meio dos jesuítas, a língua portuguesa se tornou objeto de ensino no Brasil. Segundo Favero e Molina (2017), com a necessidade de 
padronizar os procedimentos de ensino, dada a demanda, surgiu uma "sistematização da pedagogia jesuítica" que tinha "467 regras e recomendava que os professores nunca se afastassem de Aristóteles e de Sto. Tomás de Aquino." Essa sistematização tinha como foco "5 classes: Retórica, Humanidades, Gramática Superior, Gramática Média e Gramática Inferior" (FAVERO; MOLINA, p. 2).

Essa perspectiva pedagógica norteou o ensino de língua portuguesa por séculos, enraizado na concepção de que havia uma língua correta e superior, e o que dela se distanciasse não deveria ser levado em consideração. Nesse sentido, o ensino de língua restringia-se a ensino de gramática. Por sua vez, a gramática era diretamente associada às regras e construções clássicas e formais, como podemos observar nas definições a seguir, coletadas por Fávero e Molina (2017, p. 3):

Gramática portuguesa é a arte de falar e escrever corretamente a língua portuguesa (SOTERO DOS REIS, 1866)

Gramática portuguesa é a arte de falar, e escrever corretamente a língua portuguesa (FREIRE DA SILVA, 1877)

Gramática é a arte de falar e escrever corretamente: o seu objeto é, portanto, a palavra. Fala e escreve corretamente quem se conforma com as regras sancionadas pelos ditames da boa razão, e segundo os usos respeitáveis pelo assenso que granjearam dos doutos. (GRIVET, 1881)

Essas definições atestam o privilégio da norma padrão, concepção que se refletiu no ensino do século XIX, tendo mudanças apenas o final do século XX. Elas também ilustram a tese de Borges Neto (2012) de que a história do ensino de português confunde-se com o ensino da gramática do português, esse último considerado tradicionalmente a parte privilegiada da disciplina de Língua Portuguesa.

$\mathrm{Na}$ década de 1970, iniciou-se o discurso de mudança no ensino com o foco na gramática, para o ensino com foco em atividades ligadas ao texto. Porém, apesar de despertar reflexões, não houve mudanças na abordagem do ensino de língua, e a gramática tradicional continuou sendo privilegiada no contexto de ensino da língua materna. A permanência dessa concepção na escola está diretamente associada ao material de apoio de que dispõe o professor: livros didáticos e dicionários eram invariavelmente elaborados e 
construídos à luz da perspectiva teórico-metodológica da gramática tradicional (BORGES NETO, 2012).

A partir das discussões, na década de 1990, registrou-se uma quebra de paradigmas tradicionais, com destaque ao ensino de leitura e da escrita. Para o ensino de escrita, surgiu a preocupação em ir além das regras gramaticais, passando-se a considerar aspectos pragmáticos e interacionais dos textos (BORGES NETO, 2012).

$\mathrm{Na}$ primeira década de 2000, ganharam força os estudos que defendem o ensino com base nos gêneros textuais. Amplamente difundiu-se a concepção bakhtiniana de gênero como enunciados relativamente estáveis, realizados dentro de um contexto e de caráter dialógico, e do uso da língua como enunciados reais, produzidos pelas mais diversas esferas das atividades humanas e que proporcionam uma comunicação verbal podendo ser oral ou escrito (BAKHTIN, 1997, p. 280). Por sua vez, linguagem deve ser entendida como ação social e histórica, influenciada pelo contexto dos envolvidos na interação, rompendo com a concepção limitada de língua/linguagem como um código estático e rígido, sem espaço para as marcas individuais.

Nessa mesma década, as tecnologias de informação passaram a ser indicadas como auxiliares ao ensino do Português Brasileiro; o computador, o tablet, o telefone celular deveriam ser instrumentos integrantes da metodologia do professor de português, explorando os eixos da leitura, da escrita e da oralidade e, consequentemente abordando a língua em sua diversidade (BEZERRA; REINALDO, 2019, p. 5).

Em razão desse novo modo de conceber a língua na diversidade de seus usos, há a necessidade de uma prática de ensino voltada não apenas para a prescrição de regras do falar e escrever "corretamente", mas principalmente, lançar um olhar de adequação aos contextos da utilização da língua. Dados os novos estudos e perspectivas nas áreas de linguística e ensino, esse tratamento didático limitador não é mais suficiente para o trabalho com a língua portuguesa. $\mathrm{O}$ ensino da língua materna precisa ser ressignificado para dar conta dos eixos - oralidade, leitura, escrita e análise linguística - de forma articulada, reflexiva e contextualizada, e proporcionando ao aluno autonomia e plena atividade nas práticas sociais. 
A partir dessa apreciação, defendemos que o trabalho de análise linguística propõe a reflexão recorrente e organizada, que tem interesse na produção de sentidos ou na compreensão mais ampla dos usos e do sistema linguístico. Logo, o ensino pautado na prática da AL contribui para a formação de leitores e escritores de gêneros textuais diversos, aptos a participarem de eventos de letramento com autonomia e eficiência. Nesse sentido, concordamos que o aluno que consegue refletir sobre a linguagem é também capaz de compreender uma gramática. No entanto, aquele que nunca refletiu sobre a linguagem de modo amplo e contextualizado, considerando as atividades linguísticas, eplinguisticas e metalinguisticas pode se capaz de decorar as regras da gramática, mas não compreenderá seu sentido contextualizado.

O trabalho de língua não deve dissociar leitura e escrita da análise linguística. Reiteramos que o processo de escrita não deve ser entendido como pretexto para trabalhar regras gramaticais, mas, o texto escrito pelo aluno pode ser o diagnóstico do que é necessário desenvolver nas aulas com foco na análise linguística. Assim, o texto é o ponto de partida e de chegada para as reflexões sobre a linguagem que o aluno deve fazer no seu processo de aprendizagem.

O que deve ser ensinado, de acordo com os documentos oficiais, não se restringe às imposições de organização clássica de conteúdos na gramática escolar, mas aos aspectos da linguagem que precisam ser tematizados em função das necessidades apresentadas pelos alunos nas atividades de produção, leitura e escuta de textos. É essencial, em situação de ensino, propor ao aluno, a análise da língua sem separá-la de seu contexto enunciativo, buscando garantir as relações significativas estabelecidas pelos elementos linguísticos analisados.

\section{Planejamento e didatização}

Planejar é inerente ao ser humano. Historicamente, o ato de planejar acompanha a trajetória da humanidade, pois o homem primitivo, no seu contexto, criou estratégias de como fazer para superar os obstáculos corriqueiros (na caça, pesca, colheita, ataques...) e para isso, utilizou-se da habilidade de pensar, que "não deixa de ser um verdadeiro ato de 
planejar" (MENEGOLLA; SANT'ANNA, 2014, p. 13). Trata-se de um processo de previsão de necessidades e racionalização das estratégias e recursos para atingir um objetivo concreto.

$\mathrm{O}$ ato de planejar deve partir de uma avaliação diagnóstica da realidade, etapa de sondagem em que se pode estabelecer as necessidades que devem ser priorizadas no momento, enfrentando-as de forma objetiva e realista (VASCONCELOS, 2002; MENEGOLLA; SANT’ANNA, 2014). Para isso, é necessário selecionar e organizar não só atitudes, mas também materiais para atingir um dado objetivo, que pode ser flexível, dinâmico e complexo, tornando-se necessário o acompanhamento da execução e a sua avaliação. Nesse processo, o planejamento deve ser reorganizado e (re)planejado para atender os objetivos (prévios ou novos). Assim, planejar "é (uma) atividade intencional pela qual se projetam fins e se estabelecem meios para atingi-los, não é neutro, mas ideologicamente comprometido" (LUCKESI, 2011, p. 124).

Alinhando-se a essa perspectiva, Tormenta e Figueiredo (2010) defendem que o planejamento didático não é neutro, e é a parte mais importante do processo docente, pois é a ferramenta que amparará e encaminhará o modo de ação do professor. Os autores enfatizam que a ausência do planejamento não promove "uma visão geral do todo, e isso muitas vezes se revela e reflete contra o próprio docente" (TORMENTA; FIGUEIREDO, 2010, p. 03).

Assim, no universo escolar, a construção do planejamento eficiente "é o processo de decisão sobre atuação concreta dos professores, no cotidiano de seu trabalho pedagógico, envolvendo as ações e situações, em constantes interações entre professor e alunos e entre os próprios alunos" (PADILHA, 2011, p. 33). São tomadas de decisões indispensáveis a o planejamento: conhecer o contexto (suas necessidades e urgências); definir objetivos concretos e relevantes; determinar métodos e recursos (viáveis e disponíveis); estabelecer critérios para o processo e execução do planejamento; estabelecimento de etapas e prazos.

Portanto, o planejamento deve se submeter a uma constante avaliação, e reavaliação para poder, criticamente, observar como e se o objetivo está sendo alcançado. Tendo em 
vista que o planejamento deve ser flexível, esse fluxo de avaliação deve ser constante, no processo, pois, dadas as necessidades, mudanças devem ser feitas, levando em conta a racionalização do objetivo. Assim, a avaliação é mais uma etapa reflexiva no processo, pois, segundo Gandin (1998, p. 20), "no planejamento, temos em vista a ação, isto é, temos consciência de que a elaboração é apenas um dos aspectos do processo e que há necessidade da existência do aspecto da execução e do aspecto avaliação".

Logo, não é planejamento um documento que tem um viés arbitrário, individualista, estático e ditador de normas, num esqueleto rígido e inflexível. Mas é um processo que antecipa e projeta o futuro, que considera os valores e necessidades humanas. Sabendo que a educação é, para a cultura e o viver humano, um processo de transformação e de aperfeiçoamento (FREIRE, 1996; MENEGOLLA; SANT'ANNA, 2014), o planejamento na educação deve ser democrático e proporcionador de inovações.

Assim, o planejamento é cientificamente orientado, e significa mais que um projeto burocrático e neutro. Os atos de planejar e avaliar devem ser processos indispensáveis e diários no cenário educacional. Segundo Libâneo (2001, p. 84), “o planejamento é um processo contínuo de conhecimentos e análise da realidade escolar em suas condições concretas, busca de alternativas para soluções de problemas e tomadas de decisões".

O planejamento na escola deve priorizar que os conteúdos sejam organizados para atenderem às necessidades dos alunos em cada turma específica, arquitetando, assim, a mediação do aprendizado esperado. Em língua portuguesa, é importante "evitar a banalização do ensino pelo uso de atividades meramente espontâneas, assistemáticas, repetitivas, rotineira ou piegas, pois estas pouco ou nada irão contribuir para o desenvolvimento da expressão escrita do educando" (LIMA, 2006, p. 188).

Em contexto escolar, é necessário compreender que todas as turmas são heterogêneas e que é preciso planejar alcançar todos na construção de conhecimento, levando em consideração o conhecimento prévio do sujeito aluno e as possibilidades de aprendizagem em determinada turma. Dessa forma, não existe uma "receita" de como ensinar: as turmas 
são heterogêneas entre si, e em seu interior. Por essa razão, "torna-se necessária a construção da própria caminhada, de acordo com as próprias necessidades" (LIMA, 2006, p. 191) e experiências.

Por muito tempo atribuiu-se à profissão professor um caráter de dom/vocação. E sob essa visão, há uma concepção de habitus (BOURDIEU, 1989), de "intuição" e de "espontaneísmo" arraigada que se reflete na ausência de planejamento para as aulas. À luz dessa perspectiva, esse professor, geralmente, reproduz o conteúdo de uma forma mecânica e padronizada, desconsiderando os contextos heterogêneos das turmas, reiterando uma concepção apenas burocrática e inadequada do planejamento. Em contraponto a essa concepção enraizada, afirmamos, com Vasconcelos (1995, p. 143), que o planejamento

é justamente um instrumento teórico - metodológico que visa ajudar a enfrentar os desafios do cotidiano da escola, só que de uma forma refletida, consciente, sistematizada, orgânica, cientifica. E, o que é essencial, participativa. É uma metodologia de trabalho que possibilita resignificar ação de todos os agentes da escola.

Nota-se a relevância do planejamento válido, flexível, democrático, autoral, exequível, contextualizado e atualizado. Essa escrita praxiológica ${ }^{1}$ deve passar por constante avaliação do documento de planejamento para ressignificar sempre que necessário. Afinal, “a aprendizagem escolar é uma atividade intencional e dirigida, e não casual e espontânea" (LIBÂNEO, 2013, p. 92).

Quanto à noção de didatização, recorremos inicialmente ao conceito de Didática cunhado por Libâneo (2006), para referir a disciplina com foco nos estudos acerca dos objetivos - conteúdos - metodologia - execução do processo de ensino como um todo. Assim, didatizar um conteúdo é organizar e transformar o conhecimento de modo a tornálo compreensível ao aluno.

A didatização é também associada à expressão transposição didática, que, metaforicamente, consiste em tomar o diamante em seu estado bruto e lapidá-lo, transformando-

${ }^{1}$ Carnin (2016) define como escrita praxiológica a atividade escrita que o professor produz para a prática docente. 
o em pedra preciosa. De forma semelhante, o professor seleciona o conhecimento teórico a ser ensinado e o didatiza de maneira que atenda aos objetivos de ensino previamente planejados.

Nesse contexto, podemos perceber que a didatização de saberes deve considerar não só uma aula de forma singular, mas todo o contexto institucional em que está situada e aspectos sociais e culturais.

A ampliação do conceito de didatização é feita por Dolz (2016), com a expressão engenharia didática, que surge a partir de reflexões feitas em estudos no campo da didática de línguas. O autor chama a atenção para esse campo, evidenciando que essa é uma disciplina que caminha entre dois campos de conhecimento: os domínios da educação (situada entre a ciência da educação e psicologia) e da linguagem (linguística e teoria literária) (BRONCKART, 2007 apud DOLZ, 2016). Assim, a engenharia didática visa contribuir com a "elaboração de produtos, de objetos, de ferramentas profissionais e de atividades escolares destinadas ao ensino e à aprendizagem das línguas" (DOLZ, 2016, p. 238). Assim, a discussão se dá na interface das ferramentas didáticas que são concretizadas pela mobilização de saberes teóricos e os saberes práticos utilizados pelo professor. Segundo Dolz (2016, p. 241), a engenharia didática

organiza, transforma e adapta os saberes sobre a língua e as práticas discursivas para o ensino. Principalmente, a engenheira tem a responsabilidade de conceber projetos escolares e de elaborar dispositivos, atividades, exercícios, materiais escolares e novas tecnologias da comunicação escrita, oral e audiovisual. Com este objetivo, ela imagina e planifica as formas sociais de trabalho escolar dos alunos.

A partir dessa compreensão, podemos afirmar que a engenharia didática é uma base teórica agregadora para concepção e organização do planejamento de aulas. Dolz (2016) afirma que ela também contribuir para invenção de ferramentas que facilitem as aprendizagens e a orientação das intervenções profissionais do professor. Além disso "ela realiza pesquisas sobre as inovações introduzidas, controlando e avaliando a implementação das novidades.". Assim, o professor é o produtor e pesquisador de produtos e ferramentas técnicas complexas que intervêm no processo de ensino-aprendizagem. 
Para o ensino de língua, entendemos que o planejamento deve tomar como base a didatização dos gêneros textuais, no sentido de que os eixos de ensino sejam articulados e contemplados plenamente. Considerando a formação do professor, é imprescindível que durante a graduação e, mais especificamente, no componente curricular estágio supervisionado, o processo de produção e aplicação de planejamento de aulas seja repensado.

\section{Percurso metodológico da pesquisa}

\section{Tipo de pesquisa}

Estudar as práticas do ensino de língua (leitura, escrita e análise linguística) tem sido o foco de muitas pesquisas atualmente e um campo teórico surgiu para embasar essa perspectiva: A Linguística Aplicada (LA). Neste sentido, ancoramos-nos na LA pois consideramos que na perspectiva teórica apresentada por ela há uma possibilidade de pesquisa que se debruça sobre questões de língua no contexto de ensino-aprendizagem atual.

Do ponto de vista metodológico, essa pesquisa se constituiu por meio de uma abordagem híbrida, qualitativo-interpretativista, logo as reflexões construídas não consttituem julgamento de valor, mas investigação para compreender e refletir sobre os dados para contribuir com o ensino de língua materna na atualidade.

A pesquisa se configura como exploratória e documental, pois a fonte de coleta de dados está restrita a documentos (MOREIRA; CALEFFE, 2008, p. 70). Para tanto, tomamos o conceito de documentos na perspectiva de Le Goff (1997) como produto situado, repleto de significados e que estes revelam relações de força e poder. Esse conceito ultrapassa a compreensão de documento como um papel com informações, considerandoo como um documento/monumento, pois

o documento não é inócuo. É, antes de mais nada, o resultado de uma montagem, consciente ou inconsciente, das sociedades que o produziram, mas também das épocas sucessivas durantes as quais continuou a viver, talvez esquecido, durante as quais continuou a ser manipulado, ainda que pelo silêncio (LE GOFF, 1997, p. 103). 
Como visto, os documentos concretizam de forma material as intenções daqueles sujeitos (e sociedade) que os construíram, ainda que de maneira inconsciente ou involuntária. O documento materializa e revela o contexto e paradigmas que os nortearam e influenciaram. Sendo assim,

O documento é uma coisa que fica, que dura, e o testemunho, o ensinamento (para evocar a etimologia) que ele traz devem ser em primeiro lugar analisados, desmitificando-lhe o seu significado aparente. O documento é monumento. Resulta do esforço das sociedades históricas para impor ao futuro - voluntária ou involuntariamente - determinada imagem de si próprias. (LE GOFF, 1996, p. 536)

A pesquisa tem base etnográfica (ANDRÉ, 1995), pois há ênfase na inclusão da pesquisadora no contexto de observação por meio das técnicas: entrevistas com os alunos em estágio e análise dos documentos por eles produzidos. Atentamos para a construção da pesquisa na perspectiva de base etnográfica, e não etnográfica, pois para ser considerado como essa demanda maior tempo e aprofundamento na inserção do pesquisador no contexto pesquisado.

\section{Contexto, participantes e instrumentos de coleta e geração de dados}

A pesquisa foi realizada no curso de Licenciatura em Letras - Português de uma universidade pública $^{2}$. O curso oferece na grade curricular quatro componentes curriculares de estágios, que se distribuem pela área e nível de ensino: Estágio Supervisionado em Língua e em Literatura no Ensino Fundamental e Médio.

Foram participantes da pesquisa três graduandos matriculados na disciplina Estágio Supervisionado em Língua no Ensino Fundamental, nomeados aqui por³: André, Júlia e Pâmela. A escolha dos graduandos nesse contexto se deveu ao fato de ser este o primeiro componente curricular de estágio supervisionado, portanto, o primeiro contato com a sala de aula enquanto professores, e com toda estrutura e dinâmica de planejamento de aulas e

\footnotetext{
2 Aprovada pelo comitê de Ética e Pesquisa em 02 de agosto de 2019.

${ }^{3}$ Os nomes aqui apresentados são fictícios.
} 
mediação de conteúdos.

As fontes de dados documentais utilizados para a pesquisa foram: planos de aulas elaborados pelos alunos estagiários, transcrições das entrevistas semi-estruturadas ${ }^{4}$ e os relatórios de estágio.

Objetivando a triangulação dos dados, considerando Entrevista como A, Planos de aulas como $\mathbf{B}$ e Relatório como $\mathbf{C}$, a análise se dá nas seguintes relações: A - B; A - C; B - C. Optamos pelas entrevistas semiestruturadas porque elas permitiram que os entrevistados desenvolvessem as questões de forma mais pessoal e não rígida. Assim sendo, houve um direcionamento inicial, com base no roteiro de questões, mas os entrevistados têm certa liberdade nas respostas, bem como a pesquisadora questionar algo que não estava previsto inicialmente. As perguntas que compuseram o questionário foram:

1) Para você, o que é planejamento?

2) Você considera o planejamento de aulas: relevante, dispensável ou indispensável? Explique a sua resposta.

Câmara (2013) afirma que a pesquisa de abordagem qualitativa não pressupõe hipóteses pré-estabelecidas e, consequentemente, não busca dados que comprovem ou refutem essas pressuposições. Parte de questões amplas que se delineiam ao longo da pesquisa. Assim, tomamos como base a técnica de análise de conteúdo para elaborar as categorias de análise dos dados. Essa ferramenta de análise compreende três fases, a préanálise, a exploração do material e o tratamento dos resultados.

A pré-análise é uma fase de organização, a parte do primeiro contato com os documentos, e a partir desse procedimento, há a elaboração do indicadores o objetivos que nortearão a intepretação do material (CÂMARA, 2013). No caso das entrevistas, o processo de transcrição deve obedecer às regras de exaustividade, representatividade, homogeneidade, pertinência e exclusividade.

${ }^{4}$ As entrevistas aconteceram de forma oralizada e foram registradas por meio de áudio, e em seguida transcritas. 
Considerando a segunda fase da técnica de análise de conteúdo, a fase de exploração do adotamos os procedimentos de codificação, classificação e agregação. Assim, no contexto de geração de dados, a segunda fase dá conta da sistematização para categorização dos elementos para análise.

A terceira fase, tratamento dos resultados: a inferência e interpretação buscou atribuir significados aos dados identificados, organizados, selecionados e categorizados das duas fases anteriores. Para esse momento do processo, o foco está na inferência e interpretação dos dados obtidos nas entrevistas e nos planos de aulas. Nesse sentido, como procedimentos de análise buscamos:

1) Identificar e analisar os conceitos sobre planejamento;

2) Perceber e comparar a concepção de ensino de língua e como ela pode influenciar no planejamento;

3) Analisar possíveis reconfigurações conceituais e procedimentais registradas nos planos durante a realização do componente curricular.

Por fim, verificaremos as possíveis abordagens adequadas e limitações e entraves no trabalho com a articulação dos eixos propostos como objeto de investigação para indicar uma reflexão e uma proposta de trabalho.

\section{O planejamento de aulas: o que dizem e o que propõem os estagiários em letras}

Para essa análise da caraterização do planejamento tomamos como base os dados obtidos por meio das perguntas: “1) Para você, o que é planejamento?” ; e "2) Você considera o planejamento de aulas: relevante, dispensável ou insdipensável? Explique a sua resposta.", da entrevista semiestruturada, assim como a análise dos relatórios com ênfase nos termos-chave: "plano"; "planejamento"; "estrutura"; "organização" e também os planos de aulas disponibilizados pelos alunos.

Consideramos planejamento de aulas e as suas principais características, como: autoral, objetivos claros, exequível, processual (VASCONCELOS, 2002; TORMENTA E 
FIGUEIREDO, 2010; LUCKESI, 2011; MENEGOLLA E SANT’ANNA, 2014).

Consideramos "autoral" uma característica a ser abordada porque é pertinente reconhecer que cada estagiário está em um contexto distinto, e por isso deve ter as suas singularidades marcadas (LIBÂNEO, 2013). Sabemos que é importante para o exercício do professor que as suas atitudes sejam baseadas nas teorias, porém, essa perspectiva não o anula como ator e autor do agir docente.

Nesse sentido, é importante que no estágio supervisionado o planejamento seja autoral, porque além da experiência da produção para a prática docente, é o aluno da graduação que entrará em sala para atuar sob o planejado. Podemos inferir a autoria de cada estagiário. Apesar de contemplarem elementos estruturais similares, a organização, objetivos e conteúdos apresentam aspectos diferentes entre si. A estrutura geral, com informações que aparecem em todos os planos, é a seguinte:

Quadro 1: Estrutura geral dos planos de aulas

Aula (n)

Disciplina: Língua Portuguesa

Supervisor: Nome

Professora Orientadora: Nome

Professor estagiário: Nome

Turma: $\mathrm{X}$ ano

Conteúdo: XXXXX

Tempo: $\mathrm{X}$ minutos Aulas: $\mathrm{X}$

Objetivo:

Objetivos específicos:

Procedimentos metodológicos:

Recursos:

Avaliação:

Fonte: elaboração das autoras, 2020.

Esses são tópicos apresentados de forma organizada e clara em todos os planos, e neles as diferenças são marcadas pelas escolhas de elementos visuais (como marcadores de listas) e outros traços distintivos a exemplo de:

\section{I) COLABORADOR ANDRÉ}


O estagiário André, ao realizar o planejamento não anexou um plano de ensino, o que ele chama de planejamento abrangente, como defende em seu dizer:

o planejamento para o professor dentro da sala de aula, ele é tudo, porque ele vai embasar desde começo até o fim do que você quer fazer. E o planejamento, que nem XXX, voltando à XXX, ela me/ela me orientou, ela falou que o planejamento você tem que ter o planejamento abrangente, que é aquele que pega todo/todo o plano e o planejamento para cada aula. (Colaborador A, entrevista inicial, 2019)

Podemos comparar o que foi dito pelo colaborador e o apresentado em relatório e perceber que há uma diferença entre o dito e o registrado por ele nos documentos referidos. Esse dado revela uma inconsistência no dizer e fazer do estagiário. No seu registro, vemos o plano de aula da AULA 1 o qual ele subdividiu o tópico "Procedimentos metodológicos" em três: "Eixo de leitura", "Eixo de escrita" e "Eixo de gramática e análise linguística". Porém, apresenta essa estrutura subdividida apenas na nomeada AULA 1.

Observamos que o "eixo de leitura" apresenta como metodologia motivação e instigação à leitura por meio da apresentação da temática do texto e a leitura individual do conto. O "eixo de escrita" tem como procedimentos metodológicos análise dos aspectos composicionais do texto e a resposta das perguntas presentes no questionário. Já o "eixo de gramática e análise linguística", metodologicamente, objetiva o exercício de inferência dos elementos do texto, exercício de reescrita, e "foi perguntado aos alunos se eles já haviam tido algum contato com o gênero".

Nesse contexto, os dados apontam uma confusão acerca da delimitação do que compete a cada eixo, pois "reescrita do conto" e "inferência acerca dos elementos do texto" constam no eixo de gramática e análise linguística. Acreditamos que o primeiro se enquadraria melhor no eixo "escrita" enquanto o segundo pertenceria ao de "leitura".

Outro aspecto a destacar é a utilização de verbos em construção perifrásticas no passado como em "foi perguntado". Em geral, o planejamento é a organização de ações futuras, logo, não caberia para esse momento verbos no passado, relatando um acontecimento concluído. 
Apontamos que há mais uma inconsistência, pois, ora os procedimentos metodológicos se referem aos alunos, ora ao professor estagiário. Como podemos visualizar no esquema abaixo:

Imagem 1: Esquema - Objetivos do plano de aula (André)

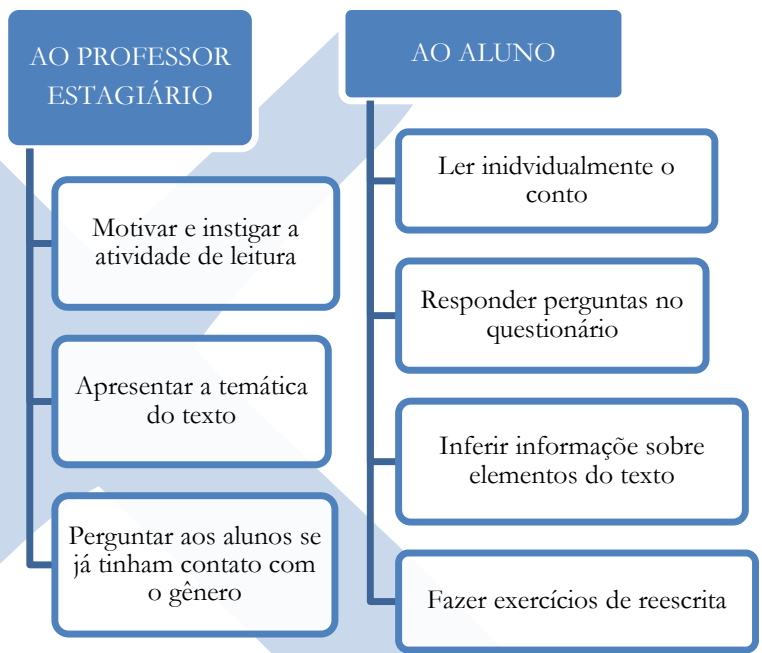

Fonte: elaboração das autoras (2020).

Consideramos que não houve uma distinção clara do que cabia ao aluno e ao professor, bem como se alguns aspectos estão mais próximos de objetivos específicos do que de procedimentos metodológicos. Essa ausência de diferenciação e confusão de conceitos não é oportuna para o plano de aulas, pois não sistematizam claramente as ações para atender os objetivos como defendido por Vasconcellos (2002) e Luckesi (2011).

\section{II) COLABORADORA JÚLIA}

Apresentou os três planos de ensino feitos durante os processos de planejamento anterior as aulas. Nesses, em forma de tabela, constam: Encontro/duração; Conteúdo; Atividade. 
Na primeira célula a colaboradora numerou a quantidade de aulas com as suas durações: 90 ou 135 minutos que correspondem a 2 ou 3 aulas respectivamente. A célula seguinte contempla os conteúdos previstos para cada um desses encontros e a terceira elenca as atividades a serem desenvolvidas tanto pela estagiária quanto pelos alunos. Os dados mostram que na célula "atividade" não fica claro para quem se destinam são essas ações, como: "Apresentar textos curtos do gênero/ Observar elementos recorrentes do gênero". Podemos inferir, ao analisar, que "apresentar" cabe à estagiária e "observar" aos alunos.

Vemos que o aspecto "flexibilidade" foi comprovado também por meio do plano de ensino dessa colaboradora quando ela apresenta os três planejamentos: o primeiro antes de apresentar ao professor -, o segundo - feito depois de apresentar ao professor -, e a terceira versão, aplicada, após as mudanças solicitadas pela professora supervisora. Esse aspecto também pôde ser observado no trecho do dizer da colaboradora:

[...] Bom, com relação ao conteúdo foi totalmente um desastre, porque eu fiz todo o planejamento com o orientador.. Ia ser sobre conto de fadas. A pro/o primeiro contato que eu tive com a professora na escola, eu pedi, eu fiz "Professora, eu tenho um/uma sequência e tal", ela fez "Não, pode ficar à vontade para escolher o seu gênero", só que quando eu fui dizer "Professora, eu vou assumir a turma", ela fez "Eu quero que você trabalhe isso, isso e isso", então foi tudo por água abaixo. (Colaboradora Júlia, entrevista inicial, 2019)

Apesar de tratar com a professora supervisora desde o início, o aspecto de (re)conhecer o contexto não foi contemplado pois a aluna não adentrou em sala para o procedimento de observação de aulas. Na sequência, os planos sofreram alterações do gênero e consequentemente, outros pontos precisaram ser revistos. No denominado de "Plano de aula: Primeira versão" o gênero é conto de fadas e os conteúdos para análise linguística são substantivo e adjetivos, há uma proposta de escrita a partir de uma reescrita do conto Chapeuzinho Vermelho. No "Plano de aula: Segunda versão" o gênero muda para conto e os conteúdos de análise linguística permanecem; para a escrita o conto reescrito é "Aconteceu naquela Tarde - Doce Vita". Já a terceira versão, a aplicada, a mudança está na parte de escrita, em que, para esse momento se planejou um conto autoral. 
Assim, vemos que para atingir os objetivos situados no contexto do estágio, a colaboradora precisou rever conteúdos, métodos e estratégias, comprovando assim, a contextualização e flexibilidade que o processo de planejar supõe (VASCONCELLOS, 2002; TORMENTA; FIGUEIREDO, 2010; LUCKESI, 2011; MENEGOLLA; SANT'ANNA, 2014).

\section{III)COLABORADORA PÂMELA}

No seu material consta um Plano de ensino que faz um planejamento geral de atividades para o período em que assumirá a turma. Nesse documento consta o Objetivo geral e específico, conteúdos, metodologia, recursos didáticos, avaliação, justificativa, fundamentação teórica, cronograma de atividades e referências bibliográficas. Chama-nos a atenção o tópico de conteúdos subdividido em: Conceituais; Procedimentais e Atitudinais.

Os conceituais dão conta dos conteúdos com foco na estrutura composicional do gênero textual (crônica) e análise linguística (adjetivos). Os procedimentais têm foco nas estratégias metodológicas despertadas e manifestadas pelos alunos no processo. E os atitudinais enfatizam as ações feitas no dia a dia pelos alunos no contexto de sala de aula.

Nesse sentido, vemos que a preocupação não se dá apenas no sentido de aplicar um conteúdo didatizado previamente, mas também (re)conhecer os alunos enquanto individuas não passivos da comunidade escolar e que para além do assunto mediado, há um ser humano em constante construção social e de aprendizagem do conteúdo.

Além dos tópicos previstos em todos os planos de aula, a colaboradora adicionou o tópico "sequência das atividades" em que, além de organizar o encadeamento dos procedimentos, estipula um tempo de duração para cada momento como nesse exemplo extraído do plano de aula para o segundo encontro:

Imagem 2: Sequência com duração de tempo de atividades

\section{Sequências das Atividades:}

Primeiro momento - Duração: 20 minutos

- Identificação de Adjetivos nas crônicas que lemos

- Reflexão acerca da função e importância dos Adjetivos 
Fonte: Plano de aula da colaboradora Pâmela, 2019.

Identificamos desse modo uma organização diferente dos outros colaboradores, comprovando a autoria e as singularidades dos planos de aulas. As aulas são divididas de dois a quatro momentos dependendo da necessidade do que está sendo proposto a cada dia. Consideramos um ponto positivo, pois além de estruturar, prevê também uma noção de tempo estimado e pode-se visualizar ainda melhor a organização da aula.

É possível perceber que os três colaboradores afirmam acreditar no planejamento de aulas como atividade importante e necessária para o professor, pois o contexto de sala de aula exige organização e que se pense sobre o que será feito.

Além disso, há uma evidência na importância da teoria aprendida na graduação sobre Planejamento, seja por meio das aulas ou das leituras preestabelecidas nas ementas dos componentes curriculares (ênfase para Planejamento e Avaliação) do curso. Reconhecer que há uma base teórica subjacente à construção do planejamento é muito importante, como defende Libâneo (2011), não é um processo neutro e é cientificamente orientado. Podemos comprovar essas afirmações a partir dos excertos que seguem:

Quadro 2: Compreensão acerca de Planejamento à luz dos colaboradores

\begin{tabular}{|c|c|c|}
\hline Colaborador & $\begin{array}{c}\text { Entrevista } \\
\text { (pergunta 1) }\end{array}$ & Relatório \\
\hline
\end{tabular}




\begin{tabular}{|c|c|c|}
\hline ANDRÉ & $\begin{array}{l}\text { É... o planejamento professor na sala de } \\
\text { aula, ele é tudo. Ele vai embasar desde o } \\
\text { começo até o fim do que você quer fazer. } \\
{[\ldots . .] \text { é fundamental, é o que vai embasar }} \\
\text { todo o conhecimento tanto do aluno } \\
\text { quanto do... Professor. }\end{array}$ & $\begin{array}{l}\text { [...] foram feitas algumas pesquisas em } \\
\text { Mengolla e Sant'Anna (2002) e em } \\
\text { Luckesi(2011) acerca dos aspectos de pla- } \\
\text { nejamentos e avaliação, com o intuito de } \\
\text { obter suporte teórico necessário para ela- } \\
\text { boração tanto do plano de aula quanto do } \\
\text { cronograma de atividades. }\end{array}$ \\
\hline JÚLIA & $\begin{array}{l}\text { Eu acho que planejamento é uma ativi- } \\
\text { dade que todo professor tem que ter an- } \\
\text { tes de entrar na sala de aula. Porque... O } \\
\text { a-aluno percebe quando você tá dando } \\
\text { uma aula "embolado", assim, você che- } \\
\text { gou lá abriu o livro didático e fez e uma } \\
\text { aula que você PENSOU. Porque eu acho } \\
\text { que quando a gente planeja uma aula, a } \\
\text { gente tá visando o aprendizado do } \\
\text { aluno... [...] Então, planejamento pra } \\
\text { mim, é uma atividade que o professor tem } \\
\text { que ter, ter como responsabilidade, } \\
\text { de/do processo de ensino e aprendiza- } \\
\text { gem desse aluno. }\end{array}$ & $\begin{array}{l}\text { Considerando o estágio como etapas, en- } \\
\text { caro como o mais árduo, complexo e sem } \\
\text { nenhuma garantia que vai dar certo, o pla- } \\
\text { nejamento. O planejamento aqui retra- } \\
\text { tado é adotado por mim e por meu orien- } \\
\text { tador, como algo que é totalmente passí- } \\
\text { vel de mudanças, ou seja, flexível e que } \\
\text { seja uma atividade que requer bastante } \\
\text { atenção, tendo em vistas os diversos pon- } \\
\text { tos que desejamos alcançar, sendo ele fins } \\
\text { e propósitos como bem aponta Luckesi } \\
\text { (2011) [...] Apesar desse grande desafio o } \\
\text { planejamento foi esquematizado em uma } \\
\text { sequência para que logo após fosse estru- } \\
\text { turado em planos. }\end{array}$ \\
\hline PÂMELA & $\begin{array}{l}\text { Como eu tive a cadeira de Planejamento } \\
\text { muito recente, então eu tenho isso muito } \\
\text { vivo na minha memória ainda, que plane- } \\
\text { jamento é simplesmente a gente se orga- } \\
\text { nizar para fazer algo. [...] acredito que o } \\
\text { planejamento ele é... Uma estratégia que a } \\
\text { gente usa durante todo o nosso dia e a } \\
\text { nossa vida para se planejar de como fazer } \\
\text { algo. Então isso quer dizer que, é... Tudo } \\
\text { o que nós fazemos durante o nosso dia } \\
\text { necessita do planejamento. Se eu hoje de- } \\
\text { cidi vir na universidade, depois fazer algo } \\
\text { depois da universidade, então é o plane- } \\
\text { jamento do meu dia, então eu acho que é } \\
\text { uma organização do que para você pre- } \\
\text { tende fazer. }\end{array}$ & \\
\hline
\end{tabular}

Fonte: elaboração das autoras (2020).

Por meio das afirmações constatamos que o colaborador André não aponta no seu relatório o que entende por planejamento, nem quais foram os critérios e aspectos evidenciados no processo de estágio, apenas a referência teórica utilizada. No entanto, em seu dizer, podemos perceber a relevância do planejamento para o prosseguimento das aulas ao considerar como base fundamental para o trabalho professor e do aluno. Logo, como propõe a Unesco (1968), não é individualista, nem arbitrário. 
Semelhante ao colaborador André a colaboradora Pâmela não apresentou conceitos sobre planejamento no seu relatório, e não mencionou os aportes teóricos que fundamentaram o processo de planejamento. Consideramos isso uma ausência significativa, pois nos relava a não importância que ela atribui ao planejamento. No entanto, no seu dizer, considera planejamento como a organização de atitudes e recursos para um determinado fim, concepção assegurada por Vasconcellos (2002) que caracteriza do planejamento como um documento consciente, sistematizado, orgânico e científico.

A colaboradora Júlia evidencia que o planejamento é necessário não só por causa do professor, mas tem a função de proporcionar um adequado processo de aprendizagem para o aluno. Ou seja, como afirmam Lima (2006) e Padilha (2011) o planejamento é produzido pelo professor, faz parte da organização do professor, mas visa à ampliação de conhecimento do aluno. Envolve o ato de pensar e refletir sobre o que fazer, como fazer e para que será feito, mesmo "sem nenhuma garantia que vai dar certo", corroborando com a concepção inicial de Menegolla e Sant'anna (2014) de planejamento como ato de pensar sobre o que será feito. Além disso, reconhece como processo feito por etapas, complexo e flexível como defendido por Tormenta e Figueiredo (2010).

Ainda sobre a concepção de planejamento, a segunda pergunta da entrevista foi: "Você considera o planejamento de aulas: relevante, dispensável ou indispensável? Explique a sua resposta." E para essa pergunta também tivemos respostas distintas, podendo ser visualizadas na tabela que segue:

Quadro 3: Respostas para pergunta 02 da entrevista inicial

\begin{tabular}{|c|l|}
\hline \multirow{3}{*}{ ANDRÉ } & $\begin{array}{l}\text { Para mim é indispensável, porque é... Eu não vou dizer é impossível, mas para uma aula } \\
\text { só não é impossível, mas para uma sequência de aula, é impossível você/você conseguir } \\
\text { realizar essa sequência de aula sem um planejamento. Porque como você vai ter embasa- } \\
\text { mento em um assunto só sendo que você não tem planejamento? }\end{array}$ \\
\hline \multirow{5}{*}{ JÚLIA } & $\begin{array}{l}\text { Indispensável. Porque eu, agora com essa experiência de estágio, eu estou vendo que eu } \\
\text { não sei como é que algum professor consegue chegar em sala de aula sem planejar. Porque } \\
\text { a gente planejando a gente já acha dificuldade, a gente já fica desesperado. [...] Porque a } \\
\text { sala de aula é uma surpresa. Você planeja uma atividade para meia hora, ela dura uma aula } \\
\text { inteira, você planeja uma atividade para uma aula inteira, ela dura meia hora, então você } \\
\text { tem que se planejar muito para ir dar uma aula. Então, para mim, é indispensável. }\end{array}$ \\
\hline & $\begin{array}{l}\text { O planejamento como um plano de aula eu acho dispensável no sentido de colocar obje- } \\
\text { tivo geral, um objetivo específico, listagem de conteúdos. Eu acho o gênero em si dis- } \\
\text { pensável no sentido de que não é prático. Na/no estágio pode até ser prático, porque é } \\
\text { com uma turma específica, num período de tempo específico, mas vendo assim, a longo }\end{array}$ \\
\hline
\end{tabular}


prazo, realmente na profissão de professor, eu não acredito que o planejamento como gênero seja algo relevante. Porém eu acredito sim que a gente não pode chegar na sala de aula só com coisas na cabeça, "Vou fazer assim, assim e assado", mas tem que ir para o caderno, tem que ir para uma folha, tem que escrever a sequência do que pensa e quanto tempo isso vai durar mais ou menos para... É um planejamento de todo modo, porém não como gênero, mas sim como um plano de como atuar.

Fonte: elaboração das autoras (2020).

André e Júlia apresentam concepções semelhantes. Eles adjetivam o planejamento como indispensável. No entanto, André assegura que para uma aula só, fora de uma sequência de aulas, é possível fazê-la sem planejar, sendo assim, dependeria mais do professor e da ciência do conteúdo da aula. Para uma sequência de aulas, então, o colaborador André reitera que é indispensável o planejamento e organização do(s) conteúdo(s) que será a base das aulas. Julia, diferentemente, não aponta exceções para o planejamento. Ele é, em sua concepção, imprescindível para o contexto de ensino. Reiterando que, mesmo com o planejamento há imprevistos e dificuldades, ou seja, sem ele, tão pouco, haveria algum benefício. A argumentação de Júlia corrobora com o que é defendido por Luckesi (2011) e Lima (2006) ao compreenderem que o planejamento é necessário para a sistematização e organização dos conteúdos, para aulas eficientes e contextualizadas.

Observa-se que o adjetivo “dispensável” para Pâmela aplica-se ao entendimento de um planejamento como gênero textual, mais burocrático, como um documento a ser preenchido. Essa concepção tangencia o que é defendido por Luckesi (2011), por exemplo, pois o autor entende o planejamento como uma sistematização e organização de conteúdos para fins reais de ensino-aprendizagem, não um papel a ser preenchido para fins meramente burocráticos.

Nesse sentido, vemos que alunos estagiários que passaram pelas mesmas disciplinas, com mesmos professores, apontam concepções teóricas e metodológicas distintas. Além disso, comprova-se a flexibilidade e autoria do gênero planejamento de aulas.

\section{Considerações finais}

Reiteramos o quão complexo e desafiador é o estágio, não só para os alunos em formação inicial, mas para todos que fazem parte do processo. Essa dupla face do estágio, 
acadêmica e social, revela, dentre outros aspectos, que o exercício docente é complexo, situado e sempre singular. $O$ estagiário transita simultaneamente entre duas dimensões: a do aprender e a do ensinar. Assim, é relevante destacar que nem sempre a experiência no estágio é natural ou branda. E que esse é um momento de lapidação do estagiário frente a complexidade do processo.

O planejamento, por sua vez, não deve ser compreendido como um documento meramente burocrático. Apenas como células a serem preenchidas e guardadas. Ele é a consolidação de um processo de pensar e prever necessidades visando atingir plenamente um dado objetivo.

Podemos observar que os estagiários têm concepções de planejamento que se aproximam e distanciam em alguns pontos. Os três reconhecem o ato de planejar como importante e necessário, porém, o modo como se planeja é singular. Os colaboradores André e Jéssica acreditam no planejamento como indispensável, e em seu dizer defendem a estruturação dos planos para um ensino de língua eficaz. A colaboradora Pâmela entende o ato de planejar como importante, mas ligado ao "pensar o que fazer em sala" e não necessariamente elaborar um documento com essa idealização.

Acreditamos que a concepção defendida por Pâmela aproxima-se do "espontaneísmo" que apontamos anteriormente, e que essa vertente não propõe um ensino de língua de modo pleno e eficaz.

\title{
PORTUGUESE LANGUAGE TEACHING IN BASIC EDUCATION: THE IMPORTANCE OF PLANNING IN THE SUPERVISED STAGE
}

\begin{abstract}
In this article we discuss the importance of mother tongue teaching (FRANCHI, 1987, GERALDI, 1997, BEZERRA; REINALDO, 2019) with a focus on teaching planning (VASCONCELOS, 2002, LUCKESI, 2011, LIBÂNEO, 2013; MENEGOLLA E SANT'ANNA, 2014). In this context, the guiding question of the research is: What do students in supervised internship understand by planning? In order to answer this question, the general objective of this article is to analyze how trainees in Literature - Portuguese Language at a public institution, plan language teaching. For collecting and creating of data semi-structured interviews were carried out with three students of the 'Letras' - Portuguese Language course enrolled in the Supervised Internship curricular components; then, the collecting of the teaching plans elaborated by them was carried out; finally, the collection of individual supervised internship reports was made. The results show that even though they are part of the same institution, attending the same periods and curricular components, employees have a different view on the relevance of planning as a praxiological writing document. It is also possible
\end{abstract}


to realize that at certain times the saying stated in the interview is not consistent with what is recorded in the documents (reports and plans). In addition, the data reveal the students' tendency to dissociate writing from linguistic analysis, and to bring the axes closer together: reading and linguistic analysis.

KEYWORDS: Didatization; Language teaching; Planning.

\section{REFERÊNCIAS}

ANDRÉ, M.E.D.A. Etnografia da prática escolar. 4. ed. Campinas: Papirus, 1995.

BAKHTIN, Mikhail. Estética da criação verbal. 2. ed. São Paulo: Martins Fontes, [1979] 1997.

BEZERRA, A. M., REINALDO, A. M.. Reflexive Teaching of Linguistic Knowledge: An Epistemological and Methodological Challenge. The Educational Review, USA, 2(4), 253-267. 2019.

BOURDIEU, P. O poder simbólico. Rio de Janeiro: Editora Bertrand Brasil S. A,1989.

BORGES NETO, José. Gramática tradicional e linguística contemporânea: continuidade ou ruptura? Todas as Letras 14(1), São Paulo: Universidade Presbiteriana Mackenzie, 2012.

CÂMARA, R. H. Análise de Conteúdo: da teoria à prática em pesquisas sociais aplicadas às organizações. Gerais: Revista Interinstitucional de Psicologia, Belo Horizonte, v. 6, n. 2, p. 179191, jul./dez. 2013

CARNIN, A. 2016. Na escrita do professor, um percurso possivel para a análise de (seu) desenvolvimento profissional. São Leopoldo, RS. Tese de Doutorado. Universidade do Vale do Rio dos Sinos, $137 \mathrm{p}$.

DOLZ, Joaquim. As atividades e os exercícios de língua: uma reflexão sobre a engenharia didática. Revista Delta, 32.1, 2016 (237 - 260) Disponível

em<http://dx.doi.org/10.1590/0102-4450321726287520541> Acesso em: 03 de fevereiro de 2018 .

FÁVERO, L. L. MOLINA, M. A. G. As concep̧̧ões linguísticas no século XIX: a gramática no Brasil. Rio de Janeiro, Editora Lucerna, 2017.

FRANCHI, C. Criatividade e gramática. Secretaria da Educação, Coordenadoria de Estudos e Normas Pedagógicas do Estado de São Paulo: São Paulo: SE/CENP, 1991 [1987].

FREIRE, P. Pedagogia da autonomia: saberes necessários à pratica educativa. São Paulo: Paz e Terra, 1996

GERALDI, J. W. O texto na sala de aulas: leitura \& produção. 2 ed. Cascavel: ASSOESTE, 1984.

Portos de passagem. 4. ed. São Paulo: Martins Fontes, 1997. GIL, B. D. Ensino de vocabulário e competência lexical. In: Gragoatá, Niterói/RJ, n. 40, 1. sem. 2016. 
GANDIN, D. Escola e transformação social. Rio de Janeiro: Vozes, 1988.

LE GOFF, Jacques. História e memória. 4. ed. Campinas: Unicamp, 1996.

LIBÂNEO, José Carlos. Didática. São Paulo: Editora Cortez, 1994.

LIMA, Maria Conceição Alves de. Textualidade e ensino: Aspectos lógico-semântico-cognitivos da linguagem e o desempenho discursivo escolar. São Paulo: UNESP, 2006.

LOPES, M. Da aplicação de Linguística à Linguística Aplicar Disciplinar. In: PEREIRA, R.C.; ROCA, P. Linguística aplicada: um caminho com diferentes acessos. São Paulo: Contexto, 2009.

LUCKESI, Cipriano Carlos. Avaliação da aprendizagem escolar: estudos e proposições. 22. ed. São Paulo: Cortez, 2011.

MENEGOLLA, Maximiliano; SANT'ANNA, Ilza Martins. Por que planejar? Como planejar? 10. ed. Petrópolis: Vozes, 2014.

MOREIRA, H; CALEFFE. L. G. Metodologia de pesquisa para o professor pesquisador. Rio de Janeiro: DP\&A, 2008.

PADILHA, R. P. Planejamento dialógico: como construir o projeto político- pedagógico da escola. São Paulo: Cortez, 2011.

SILVA, W. R. Reflexão pela escrita no estágio supervisionado da licenciatura: pesquisa em Linguística Aplicada. Campinas: Pontes Editores, 2014.

TORMENTA, A.A. e FIGUEIREDO, J.A. Planejamento: a importância do plano de trabalho docente na prática pedagógica. In: PARANÁ. Secretaria de Estado da Educação. Superintendência de Educação. O professor PDE e os desafios da escola pública paranaense, v.1, 2010.

VASCONCELOS, Celso. S. Formação didática do educador contemporâneo: desafios e perspectivas. In: UNIVERSIDADE ESTADUAL PAULISTA. Prograd. Caderno de Formação: formação de professores didática geral. São Paulo: Cultura Acadêmica, 2011, p. 3358, v. 9 .

Recebido em: 30/04/2020.

Aprovado em: 25/05/2020. 